\title{
Factors associated with adherence to antiretroviral therapy among HIV infected children in Kabale district, Uganda: a cross sectional study
}

\author{
Ignatius Wadunde ${ }^{1 *}$, Doreen Tuhebwe ${ }^{1}$, Michael Ediau$^{1}$, Gildo Okure ${ }^{1}$, Arthur Mpimbaza²
} and Rhoda K. Wanyenze ${ }^{3}$

\begin{abstract}
Objectives: This study was set out to assess the level of adherence to antiretroviral therapy (ART) and its determinants among children receiving HIV treatment in Kabale district, south western Uganda, in order to inform interventions for improving pediatric ART adherence.

Results: Overall, 79\% (121/153) of the children did not miss ART doses over the 7 days. Caregiver forgetfulness was the major reason for missing ART doses, 37\% (13/35). Other reasons included transportation costs to the health facilities, 17\%, (6/35) and children sitting for examinations in schools. Older children (11-14 years) were more likely to adhere to ART than the younger ones ( $0-10$ years) $(A O R=6.41,95 \% \mathrm{Cl} 1.31-31.42)$. Caregivers, who knew their HIV status, had their children more adherent to ART than the caregivers of unknown HIV status (AOR $=21.64: 95 \% \mathrm{Cl}$ 1.09-428.28). A significant proportion of children in two facilities $21.5 \%$ (32/153) missed ART doses within the previous week. Support for providers to identify clues or reminders to take drugs, extending HIV testing to caregivers and innovative models of ART delivery that alleviate transport costs to caregivers and allow sufficient drugs for children in school could enhance drug adherence among children.
\end{abstract}

Keywords: Pediatric, Adherence, Antiretroviral therapy

\section{Introduction}

Antiretroviral therapy (ART) improves health and prolongs the lives of persons with HIV [1-3] and in children, adherence to ART reduces viral load $[4,5]$, HIV/ AIDS related morbidity [6] and mortality [7, 8]. Access to ART has rapidly expanded globally and in sub Saharan Africa especially with the most recent changes in the World Health Organization (WHO) guidelines to allow early treatment for HIV infected individuals [9]. However, implementation of ART among children $0-14$ years, faces major challenges of adherence [10].

\footnotetext{
*Correspondence: iwadunde@gmail.com

1 Department of Health Policy, Planning and Management, Makerere University College of Health Sciences School of Public Health, P.O Box 7072, Kampala, Uganda

Full list of author information is available at the end of the article
}

Better Socio-economic status and well tolerated regimens are associated with better adherence [11]. Other factors like socio-demographic and socio-cultural factors, side effects of ARVs, ART regimes, drug dosing [12, 13], duration on ART [14], health of child [5], child knowledge of their HIV status [15], and psychosocial factors such as stress, depression and anxiety [11] have also been associated with pediatric ART adherence $[5,16]$.

The Care giver report has been used as a simple and vital method in assessing pediatric ART adherence in Africa $[5,11,17]$.

Thirteen percent of the people living with HIV/AIDS in Uganda are children $[18,19]$, and all HIV positive children less than 15 years $(0-14)$ are initiated on ART irrespective of the CD4 count or WHO clinical staging [20]. To ensure retention in HIV care and adherence to HIV 
treatment, there should be constant supply of antiretroviral drugs (ARV's), psychological support and HIV status disclosure by care giver with support of a counselor for children aged 10 and above $[9,20,21]$.

In Kabale district, there were 564 HIV positive children aged 0-14 years and reports from the district health office indicated low adherence to ART. This study set out to determine the level of adherence and its associated factors among HIV infected children aged 0-14 years in Kabale district, so as to inform efforts for improving ART adherence among HIV infected children.

\section{Main text Method}

We conducted a quantitative cross sectional study between June and August 2014 in Kabale district located in south western Uganda, with an estimated regional HIV prevalence of $5 \%[22,23]$. The district has twenty two health facilities providing pediatric ART; however, this study was conducted in two hospitals of Rugarama (private) and Kabale regional referral (public). These hospitals were deliberately selected because they provide HIV treatment to the largest number of HIV infected children in the district.

We interviewed 153 caregivers of HIV infected children aged $0-14$ years receiving ART in the two hospitals. The caregivers had to be 18 years and above, age at which they could give informed consent and the eligible children were those who had been on ART for at least 3 months prior the interview. This study, since it was a cross sectional study, the sample size was determined from the formula for estimating sample sizes for prevalence studies [24].

The caregivers of the sampled children were interviewed using a pre-tested, semi-structured questionnaire translated into Rukiga, the predominant local language in Kabale district. The interviews were administered by trained study nurses fluent in Rukiga, the local language.

We assessed several factors that were suspected to influence ART adherence as informed from the literature review. The child related factors included age and health status of the child, knowledge of their HIV status and duration on ART [5, 15] [17]. The caregiver factors included the caregiver's relationship with the child, stress and depression, age, sex, occupation, highest level of education attained, and duration as child's caregiver [11, 15]. The drug regimen for each child was documented in addition to the other medication factors such as side effects of the ART, drug dosing and tolerability $[5,11,15]$. We also assessed caregiver forgetfulness to remind their HIV infected children on ART to take their medication on time, since it has been found to affect the child's adherence [15].

The dependent variable was adherence to ART in the last 7 days as reported by the caregiver. Adherence measurement was based on the caregivers report of missed ART doses in the last 7 days prior to the interviews [15] and similar adherence studies used a 3 days recall [17]. It was characterized as "optimal adherence versus poor adherence". Children whose caregivers reported no missed doses were considered to have optimal adherence to ART while those who reported one or more missed doses were considered to have poor adherence.

After questionnaires had been checked, the data was entered using Epi Info software and exported to Stata software for analysis. At Univariate analysis, categorical variables were analyzed using frequencies and proportions and continuous variables using means and standard deviations. The percentage of children with good adherence was calculated by dividing the number of care givers who reported that their children did not miss any dose within the last 7 days prior the interview by the total number of caregivers interviewed.

$\mathrm{Bi}$-variable analysis was done to determine the relationship between each independent factor and adherence. Multivariate logistic regression was done on all factors that were significant after bi-variable analyses to identify factors independently associated with ART adherence. The association of independent variables with the dependent variable was measured using odds rations and the corresponding 95\% confidence intervals (CI). A $p$ value of $<0.05$ was considered statistically significant.

\section{Results and discussion}

All the 153 caregivers who were approached agreed to participate and were interviewed. Most of the sampled children $(84.3 \%, 129 / 153)$ were enrolled from Kabale regional referral hospital. Most of the caregivers were in the $31-40$ year age group, $40.1 \%,(62 / 153)$, and majority of the caregivers were females, $73.9 \%$ (113/153), had primary level of education $37.9 \%$ (58/153), were peasants, $47.6 \%(70 / 153)$ and $78.4 \%(120 / 153)$ were biological parents of the children. Of the 153 children, 56.2\% (86/153) were females and the majority, $85.1 \%,(131 / 153)$ were above 5 years of age.

Details of the socio-demographics for the children and caregivers are shown in Table 1.

\section{Level of adherence to ART}

Overall, 79.1\% (121/153) of the children did not miss any ART doses over the 7 days. Thirty-five children (20.9) missed at least one dose within a period of 7 days. The commonest reasons for missing doses were forgetfulness, $34 \%(13 / 35)$, transportation costs to the health facilities, 
Table 1 Socio-demographic characteristics of caregivers and children on ART, Kabale, Uganda 2014

\begin{tabular}{|c|c|c|}
\hline Characteristic & $\begin{array}{l}\text { Frequency } \\
(n=153)\end{array}$ & Proportion (\%) \\
\hline \multicolumn{3}{|l|}{ Age of child } \\
\hline $0-4$ years & 23 & 14.94 \\
\hline $5-10$ years & 66 & 42.86 \\
\hline $11-14$ years & 65 & 42.21 \\
\hline \multicolumn{3}{|l|}{ Gender of child } \\
\hline Female & 86 & 56.21 \\
\hline Male & 67 & 43.79 \\
\hline \multicolumn{3}{|l|}{ Age of care giver } \\
\hline$\leq 20$ years & 23 & 14.94 \\
\hline $21-30$ years & 42 & 27.27 \\
\hline $31-40$ years & 62 & 40.26 \\
\hline$>41$ years & 27 & 17.53 \\
\hline \multicolumn{3}{|l|}{ Sex of care giver } \\
\hline Female & 113 & 73.86 \\
\hline Male & 40 & 26.14 \\
\hline \multicolumn{3}{|c|}{ Level of education of care giver } \\
\hline None & 23 & 15.03 \\
\hline Primary & 58 & 37.91 \\
\hline Secondary & 39 & 25.49 \\
\hline Tertiary & 33 & 21.57 \\
\hline \multicolumn{3}{|l|}{ Occupation of care giver } \\
\hline Peasant & 70 & 47.62 \\
\hline Small business operator & 37 & 25.17 \\
\hline Civil servant & 25 & 17.01 \\
\hline Other ${ }^{\mathrm{a}}$ & 15 & 9.8 \\
\hline \multicolumn{3}{|c|}{ Care giver relationship with child } \\
\hline Biological parent & 120 & 78.43 \\
\hline Sibling & 5 & 3.27 \\
\hline Other relative & 27 & 17.65 \\
\hline Not related & 1 & 0.65 \\
\hline
\end{tabular}

a Other (students, housewife, petty jobs)

$17 \%(6 / 35)$ and children sitting for examinations at school, 17\% (6/35).

Seventeen caregivers reported various side effects of ART including dizziness, 23\% (4/17), vomiting, 18\% (3/17), stomach pain, $11 \%(2 / 17)$, rashes, $18 \%(3 / 17)$, headaches, $18 \%(3 / 17)$ and fever, $11 \%(2 / 17)$ (Table 2).

\section{Factors associated with adherence to antiretroviral therapy}

After controlling for child age, duration on ART, knowledge of their HIV status, age of caregiver, caregiver level of education, caregiver relationship with child and caregiver knowing their HIV status, child age and caregiver knowledge of their HIV status had significant associations with adherence.
Table 2 Reasons for missing ART doses and side effects of ART among HIV children on ART, Kabale, Uganda 2014

\begin{tabular}{lll}
\hline Characteristic & Frequency & Proportion (\%) \\
\hline Reasons for missing dose & $(\mathrm{n}=35)$ & \\
Caregiver forgetfulness & 13 & 37.1 \\
Transportation problems & 6 & 17.1 \\
School examinations & 6 & 17.1 \\
Children went playing & 5 & 14.3 \\
Child vomited drug & 4 & 11.4 \\
Drug run out & 1 & 2.9 \\
\hline
\end{tabular}

Older children (11-14 years) were more likely to adhere to ART than the younger ones (0-10 years) AOR 6.41 (95\%CI 1.31-31.42) p-value 0.022. Children of Caregivers who knew their HIV status were more likely to adhere to ART than those whose caregivers did not know their HIV status AOR 21.64 (1.09-429.24) p-value 0.044 (Table 3).

Caregiver forgetfulness was a major (37\%) reason for missing ART doses. This can be improved by advising the caregivers to give the children the medicines consistently at the same convenient time of the day and using clues to remind them to give the child their drugs [25, 26]. The other reason for missing ART doses were transportation to facilities for drug refills. Transportation cost as a limitation for appointment keeping and drug refills has been reported by studies among children and adults [27, 28]. Community based refills for stable patients can alleviate such challenges and also improve efficiencies for service delivery [29].

Our study found that older children (11 years and above) were more likely to adhere to ART than younger ones ( $0-10$ years), and this is in line with findings from Ethiopia [30]. Older children have better awareness and appreciation of the negative effects of poor ART adherence, especially if their HIV status has been disclosed to them [25]. Providers should thus pay more attention to the younger children and provide support to caregivers to bridge the gaps.

Our study also found that caregivers who knew their HIV status, had their HIV infected children more likely to adhere to ART compared to the children of the caregivers who did not know their HIV status. This implies that all caregivers of HIV infected children should be advised to know their HIV status, enhances their HIV infected children to adhere to their medication.

\section{Conclusions}

The level of adherence to antiretroviral therapy was found to be sub optimal, a significant proportion of children, 21\% (35/153) missed their drugs.

Caregiver knowledge of their HIV status was associated with pediatric ART adherence, so there is need to 
Table 3 Factors associated with adherence to ART doses among HIV infected Children 0-14 years in Kabale district, Uganda

\begin{tabular}{|c|c|c|c|c|c|c|c|c|}
\hline \multirow[t]{2}{*}{ Variable } & \multicolumn{7}{|l|}{ Adherent } & \multirow[t]{2}{*}{ p-value } \\
\hline & $\begin{array}{l}\text { Yes } \\
(n=121)\end{array}$ & $\begin{array}{l}\text { No } \\
(n=32)\end{array}$ & COR & $95 \% \mathrm{Cl}$ & & AOR & $95 \% \mathrm{Cl}$ & \\
\hline \multicolumn{9}{|l|}{ Study site } \\
\hline Rugarama hospital & $3(9.38)$ & $20(16.95)$ & 1.0 & & & & & \\
\hline Kabale hospital & $29(90.63)$ & $98(83.05)$ & 0.5 & $(0.14-1.83)$ & & & & \\
\hline \multicolumn{9}{|l|}{ Age of child } \\
\hline $0-10$ years & $19(59.38)$ & $68(57.14)$ & 1.0 & & & 1.0 & & \\
\hline $11-14$ years & $13(40.63)$ & $51(42.86)$ & 1.1 & $(0.49-2.42)$ & & 6.4 & $(1.31-31.42)$ & $0.022^{*}$ \\
\hline \multicolumn{9}{|l|}{ Gender of child } \\
\hline Female & $16(50.00)$ & $68(58.12)$ & 1.0 & & & & & \\
\hline Male & $16(50.00)$ & $49(41.88)$ & 0.7 & $(0.33-1.58)$ & & & & \\
\hline \multicolumn{9}{|l|}{ Child duration on ART } \\
\hline $0-4$ years & $14(43.75)$ & $58(49.15)$ & 1.0 & & & 1.0 & & \\
\hline 5 years above & $18(56.25)$ & $60(50.85)$ & 0.8 & $0.37-1.77$ & & 1.2 & $(0.39-3.58)$ & 0.768 \\
\hline \multicolumn{9}{|l|}{ Childs'health } \\
\hline Not sick by time of interview & $28(87.50)$ & $108(91.5)$ & 1.0 & & & & & \\
\hline Sick time of interview & $4(12.50)$ & $10(8.47)$ & 0.7 & $(0.19-2.22)$ & & & & \\
\hline \multicolumn{9}{|l|}{ Sex of care giver } \\
\hline Female & $23(71.88)$ & $88(74.58)$ & 1.0 & & & & & \\
\hline Male & $9(28.13)$ & $30(25.42)$ & 0.9 & $(0.36-2.09)$ & & & & \\
\hline \multicolumn{9}{|l|}{ Age of care giver } \\
\hline$\leq 30$ years & $13(40.63)$ & $51(42.86)$ & 1.0 & & & 1.0 & & \\
\hline 30 years above & $19(59.38)$ & $68(57.14)$ & 0.9 & $(0.41-2.01)$ & & 0.8 & $(0.44-1.49)$ & 0.499 \\
\hline \multicolumn{9}{|l|}{ Level of education of care giver } \\
\hline None & $4(12.50)$ & $19(16.10)$ & 1.0 & & & & & \\
\hline Primary & $14(43.75)$ & $43(36.44)$ & 0.7 & $(0.19-2.22)$ & & 0.38 & $(0.06-2.40)$ & 0.307 \\
\hline Secondary & $4(12.50)$ & $33(27.97)$ & 1.7 & $(0.39-7.76)$ & & 2.26 & $(0.2-20.95)$ & 0.474 \\
\hline Tertiary & $10(31.25)$ & $23(19.49)$ & 0.5 & $(0.13-1.79)$ & & 0.16 & $(0.02-1.21)$ & 0.077 \\
\hline \multicolumn{9}{|l|}{ Occupation of care giver } \\
\hline Formal employment & $23(76.67)$ & $96(84.21)$ & 1.0 & & & & & \\
\hline Informal employment & $7(23.33)$ & $18(15.79)$ & 0.6 & $(0.23-1.66)$ & & & & \\
\hline \multicolumn{9}{|l|}{ Care giver relationship with child } \\
\hline Biological parent & $24(77.42)$ & $93(78.81)$ & 1.0 & & & 1.0 & & \\
\hline Other relative & $7(22.58)$ & $25(21.19)$ & 0.9 & $(0.36-2.39)$ & & 0.3 & $(0.07-1.70)$ & 0.189 \\
\hline \multicolumn{9}{|l|}{ Duration as caregiver of child } \\
\hline $0-4$ years & $13(40.63)$ & $51(42.86)$ & 1.0 & & & & & \\
\hline 5 years above & $19(59.38)$ & $68(57.14)$ & 0.9 & $(0.41-2.02)$ & & & & \\
\hline \multicolumn{9}{|l|}{ Care giver's health } \\
\hline Not sick a week before interview & $25(80.65)$ & $100(85.5)$ & 1.0 & & & & & \\
\hline Sick a week before interview & $6(19.35)$ & $17(14.5)$ & 0.7 & $(0.25-1.99)$ & & & & \\
\hline \multicolumn{9}{|c|}{ Caregiver knowledge of his/her HIV status } \\
\hline Do not know their HIV status & $5(16.13)$ & $9(7.63)$ & & & & & & \\
\hline Know their HIV status & $26(83.87)$ & $109(92.4)$ & 2.3 & $0.71-7.63$ & 0.15 & 21.6 & $1.09-428.2$ & $0.044^{*}$ \\
\hline \multicolumn{9}{|l|}{ Care giver stress } \\
\hline Not stressed & $29(90.63)$ & $97(81.5)$ & 1.0 & & & & & \\
\hline Stressed & $3(9.38)$ & $22(18.5)$ & 2.2 & $(0.61-7.94)$ & & & & \\
\hline
\end{tabular}


Table 3 (continued)

\begin{tabular}{|c|c|c|c|c|c|c|c|c|}
\hline \multirow[t]{2}{*}{ Variable } & \multicolumn{7}{|l|}{ Adherent } & \multirow[t]{2}{*}{ p-value } \\
\hline & $\begin{array}{l}\text { Yes } \\
(n=121)\end{array}$ & $\begin{array}{l}\text { No } \\
(n=32)\end{array}$ & COR & $95 \% \mathrm{Cl}$ & & AOR & $95 \% \mathrm{Cl}$ & \\
\hline \multicolumn{9}{|l|}{ Drug tolerability } \\
\hline Child does not find a problem swallowing & $31(96.88)$ & $110(97.4)$ & 1.0 & & & & & \\
\hline Child finds swallowing the drug a problem & $1(3.13)$ & $3(2.65)$ & 0.9 & $(0.08-8.48)$ & 0.886 & & & \\
\hline \multicolumn{9}{|l|}{ Drug dosage complexity } \\
\hline Child find dose easy to take & $30(93.75)$ & $105(90.5)$ & & & & & & \\
\hline Child find dose not easy to take & $2(6.25)$ & $11(9.48)$ & 1.6 & $(0.33-7.53)$ & 0.569 & & & \\
\hline \multicolumn{9}{|l|}{ Side effects of the ARV's } \\
\hline Child has never experienced drug side effects & $26(83.87)$ & $107(89.9)$ & & & & & & \\
\hline Child has experienced a side effect due to the ARV's & $5(16.13)$ & $12(10.1)$ & 0.6 & $(0.19-1.81)$ & 0.346 & & & \\
\hline
\end{tabular}

*Statistically significant

integrate efforts to enhance caregivers of HIV infected children to know their HIV status. Caregiver forgetfulness and transportation challenges also led to missed doses.

\section{Limitations}

In our study, we recognize a major limitation of the use of a small sample size (153) that gave rise to very wide confidence intervals. Caregiver reports of missed ART doses to assess adherence, is also a less objective measure of adherence because it leads to over estimation of adherence, recall bias and social desirability bias.

\section{Abbreviations}

ART: adherence to antiretroviral therapy; ARV's: antiretroviral drugs; Cl: confidence interval; HDREC: Higher Degrees Research and Ethics Committee; WHO: World Health Organization.

\section{Authors' contributions}

IW: Conceived and implemented the study, supervised data collection, analyzed the data and wrote the first version of the manuscript. DT, ME, AM and GO supported IW in conceptualizing and designing the study and participated in data analysis, interpretation of results and reviewed the draft manuscript. RKW: Participated in data analysis, interpretation and reviewed the draft manuscript for substantial intellectual content. All authors read and approved the final manuscript.

\footnotetext{
Author details

${ }^{1}$ Department of Health Policy, Planning and Management, Makerere University College of Health Sciences School of Public Health, P.O Box 7072, Kampala, Uganda. ${ }^{2}$ Child Health and Development Centre, Makerere University College of Health Sciences School of Medicine, P.O. Box 6717, Kampala, Uganda.

${ }^{3}$ Department of Disease Control and Environmental Health, Makerere University College of Health Sciences School of Public Health, P.O Box 7072, Kampala, Uganda.
}

\section{Acknowledgements}

We thank the study participants for their participation in the study. We would also like to extend our heartfelt gratitude to the study Nurses (Research Assistants) at Kabale regional referral hospital and Rugarama hospital who helped with data collection.

\section{Competing interests}

The authors declare that they have no competing interests.

\section{Availability of data and materials}

Data used in this analysis are made available to all interested researchers upon request directed to the author Mr.Wadunde Ignatius (iwadunde@gmail.com).

\section{Consent for publication}

Not applicable.

\section{Ethics approval and consent to participate}

Ethical clearance was obtained from the Makerere University School of public Health Higher Degrees Research and Ethics Committee (HDREC) and permission sought from relevant officials in the district and selected health facilities. All consent forms were translated into the local language (Rukiga) and backtranslated into English to ensure correct use of language. Consent forms were read aloud to caregivers by trained study nurses. The consent forms described the purpose of the study, procedures involved, and the risks and benefits of participation. Consent was obtained from a parent or caregiver on behalf of the participants who were under the age of 16. The interviews were conducted in private rooms and confidentiality of data protected through the use of identification numbers rather than names and limiting access to the data.

\section{Funding}

This study was funded by Makerere University School of Public Health through Cooperative Agreement Number: 5U2GGH000817-03 ("Provision of Comprehensive HIV/AIDS services and developing national capacity to manage HIV/AIDS Programs in Uganda") from the US-Centers for Disease Control and Prevention. The contents of this article are however solely the responsibility of the authors and do not necessarily represent the views of the US-Centers for Disease Control and Prevention and Makerere University School of Public Health.

\section{Publisher's Note}

Springer Nature remains neutral with regard to jurisdictional claims in published maps and institutional affiliations.

Received: 18 February 2018 Accepted: 6 July 2018

Published online: 13 July 2018

\section{References}

1. Bradley H, Hall HI, Wolitski RJ, Van Handel MM, Stone AE, LaFlam M, Skarbinski J, Higa DH, Prejean J, Frazier EL. Vital signs: HIV diagnosis, care, and 
treatment among persons living with HIV—United States, 2011. Morb Mortal Wkly Rep. 2014;63(47):1113-7.

2. Oguntibeju OO. Quality of life of people living with HIV and AIDS and antiretroviral therapy. HIV/AIDS. 2012;4:117.

3. Thompson MA, Aberg JA, Hoy JF, Telenti A, Benson C, Cahn P, Eron JJ, Günthard HF, Hammer SM, Reiss P. Antiretroviral treatment of adult HIV infection: 2012 recommendations of the International Antiviral SocietyUSA panel. JAMA. 2012;308(4):387-402.

4. Nabukeera-Barungi N, Kalyesubula I, Kekitiinwa A, Byakika-Tusiime J, Musoke P. Adherence to antiretroviral therapy in children attending Mulago Hospital, Kampala. Ann Trop Paediatr. 2007;27(2):123-31.

5. Williams PL, Storm D, Montepiedra G, Nichols S, Kammerer B, Sirois $\mathrm{PA}$, Farley J, Malee K. Predictors of adherence to antiretroviral medications in children and adolescents with HIV infection. Pediatrics. 2006;118(6):e1745-57.

6. Biressaw S, Abegaz WE, Abebe M, Taye WA, Belay M. Adherence to antiretroviral therapy and associated factors among HIV infected children in Ethiopia: unannounced home-based pill count versus caregivers' report. BMC Pediatr. 2013;13(1):132.

7. Greub G, Ledergerber B, Battegay M, Grob P, Perrin L, Furrer H, Burgisser P, Erb P, Boggian K, Piffaretti J-C. Clinical progression, survival, and immune recovery during antiretroviral therapy in patients with HIV-1 and hepatitis C virus coinfection: the Swiss HIV Cohort Study. Lancet. 2000;356(9244):1800-5.

8. Wiktor SZ, Sassan-Morokro M, Grant AD, Abouya L, Karon JM, Maurice C, Djomand G, Ackah A, Domoua K, Kadio A. Efficacy of trimethoprimsulphamethoxazole prophylaxis to decrease morbidity and mortality in HIV-1-infected patients with tuberculosis in Abidjan, Cote d'Ivoire: a randomised controlled trial. Lancet. 1999;353(9163):1469-75.

9. Organization WH. Consolidated guidelines on the use of antiretroviral drugs for treating and preventing HIV infection: recommendations for a public health approach. Geneva: World Health Organization; 2016.

10. Marhefka SL, Tepper VJ, Farley JJ, Sleasman JW, Mellins CA. Brief report: assessing adherence to pediatric antiretroviral regimens using the 24-hour recall interview. J Pediatr Psychol. 2006;31 (9):989-94.

11. Davies M-A, Boulle A, Fakir T, Nuttall J, Eley B. Adherence to antiretroviral therapy in young children in Cape Town, South Africa, measured by medication return and caregiver self-report: a prospective cohort study. BMC Pediatr. 2008;8(1):34.

12. Ingersoll KS, Cohen J. The impact of medication regimen factors on adherence to chronic treatment: a review of literature. J Behav Med. 2008;31(3):213-24.

13. Paterson DL, Swindells S, Mohr J, Brester M, Vergis EN, Squier C, Wagener MM, Singh N. Adherence to protease inhibitor therapy and outcomes in patients with HIV infection. Ann Intern Med. 2000;133(1):21-30.

14. Nozaki I, Dube C, Kakimoto K, Yamada N, Simpungwe JB. Social factors affecting ART adherence in rural settings in Zambia. AIDS Care. 2011;23(7):831-8.

15. Biadgilign S, Deribew A, Amberbir A, Deribe K. Adherence to highly active antiretroviral therapy and its correlates among HIV infected pediatric patients in Ethiopia. BMC Pediatr. 2008:8(1):53.
16. Sahay S, Reddy KS, Dhayarkar S. Optimizing adherence to antiretroviral therapy. Indian J Med Res. 2011;134(6):835.

17. Mghamba FW, Minzi OM, Massawe A, Sasi P. Adherence to antiretroviral therapy among HIV infected children measured by caretaker report, medication return, and drug level in Dar Es Salaam, Tanzania. BMC Pediatr. 2013;13(1):95

18. Downing J, Birtar D, Chambers L, Gelb B, Drake R, Kiman R. Children's palliative care: a global concern. Int J Palliat Nurs. 2012;18(3):109-14.

19. Mutumba M, Bauermeister JA, Musiime V, Byaruhanga J, Francis K, Snow RC, Tsai AC. Psychosocial challenges and strategies for coping with HIV among adolescents in Uganda: a qualitative study. AIDS Patient Care STDs. 2015;29(2):86-94.

20. Uganda Ministry of Health $(\mathrm{MOH})$. Addendum to the national antiretroviral treatment guidelines. Kampala, Uganda: $\mathrm{MOH} ; 2013$.

21. Bikaako-Kajura W, Luyirika E, Purcell DW, Downing J, Kaharuza F, Mermin J, Malamba S, Bunnell R. Disclosure of HIV status and adherence to daily drug regimens among HIV-infected children in Uganda. AIDS Behav. 2006;10(1):85.

22. Kakaire O, Osinde MO, Kaye DK. Factors that predict fertility desires for people living with HIV infection at a support and treatment centre in Kabale, Uganda. Reprod Health. 2010;7(1):27.

23. Osinde MO, Kakaire O, Kaye DK. Factors associated with disclosure of HIV serostatus to sexual partners of patients receiving HIV care in Kabale, Uganda. Int J Gynecol Obstet. 2012;118(1):61-4.

24. Charan J, Biswas T. How to calculate sample size for different study designs in medical research? Indian J Psychol Med. 2013;35(2):121-6.

25. Arage G, Tessema GA, Kassa H. Adherence to antiretroviral therapy and its associated factors among children at South Wollo Zone Hospitals, Northeast Ethiopia: a cross-sectional study. BMC public health. 2014;14(1):365.

26. Reda AA, Biadgilign S. Determinants of adherence to antiretroviral therapy among HIV-infected patients in Africa. AIDS Res Treat. 2012;2012:574656.

27. Murray LK, Semrau K, McCurley E, Thea DM, Scott N, Mwiya M, Kankasa C, Bass J, Bolton P. Barriers to acceptance and adherence of antiretroviral therapy in urban Zambian women: a qualitative study. AIDS Care. 2009;21(1):78-86.

28. Wasti SP, Simkhada P, Randall J, Freeman JV, Van Teijlingen E. Factors influencing adherence to antiretroviral treatment in Nepal: a mixed-methods study. PLoS ONE. 2012;7(5):e35547.

29. Rasschaert F, Decroo T, Remartinez D, Telfer B, Lessitala F, Biot M, Candrinho B, Van Damme W. Adapting a community-based ART delivery model to the patients' needs: a mixed methods research in Tete, Mozambique. BMC Public Health. 2014;14(1):364.

30. Dachew BA, Tesfahunegn TB, Birhanu AM. Adherence to highly active antiretroviral therapy and associated factors among children at the University of Gondar Hospital and Gondar Poly Clinic, Northwest Ethiopia: a cross-sectional institutional based study. BMC Public health. 2014;14(1):875

Ready to submit your research? Choose BMC and benefit from:

- fast, convenient online submission

- thorough peer review by experienced researchers in your field

- rapid publication on acceptance

- support for research data, including large and complex data types

- gold Open Access which fosters wider collaboration and increased citations

- maximum visibility for your research: over $100 \mathrm{M}$ website views per year

At BMC, research is always in progress.

Learn more biomedcentral.com/submissions 